\title{
Ethanol extract separated from Sargassum horneri (Turner) abate LPS-induced inflammation in RAW 264.7 macrophages
}

K. K. Asanka Sanjeewa ${ }^{1}$, Thilina U. Jayawardena ${ }^{1}$, Hyun-Soo Kim', Seo-Young Kim', Ginnae Ahn², Hak-Ju Kim³, Xiaoting $\mathrm{Fu}^{4}$, Youngheun Jee ${ }^{5^{*}}$ and You-Jin Jeon ${ }^{1 *}$ (I)

\begin{abstract}
Background: This study is aimed at identifying the anti-inflammatory properties of 70\% ethanol extract produced from an edible brown seaweed Sargassum horneri (SJB-SHE) with industrial-scale production by Seojin Biotech Co. Ltd. S. horneri is a rich source of nutrient and abundantly growing along the shores of Jeju, South Korea.

Methods: Here, we investigated the effect of SJB-SHE on LPS-activated RAW 264.7 macrophages. The cytotoxicity and NO production of SJB-SHE were evaluated using MTT and Griess assays, respectively. Additionally, protein expression and gene expression levels were quantified using ELISA, Western blots, and RT-qPCR.

Results: Our results indicated that pre-treatment of RAW 264.7 macrophages with SJB-SHE significantly inhibited LPS-induced $N O$ and $\mathrm{PGE}_{2}$ production. SJB-SHE downregulated the proteins and genes expression of LPS-induced iNOS and COX2. Additionally, SJB-SHE downregulated LPS-induced production of pro-inflammatory cytokines (tumor necrosis factor-a, interleukin (IL)-6, and IL-1ß). Furthermore, SJB-SHE inhibited nuclear factor kappa-B (NF-kB) activation and translocation to the nucleus. SJB-SHE also suppressed the phosphorylation of mitogen-activated protein kinases (ERK1/2 and JNK).
\end{abstract}

Conclusions: Collectively, our results demonstrated that SJB-SHE has a potential anti-inflammatory property to use as a functional food ingredient in the future.

Keywords: Sargassum horneri, Ethanol extract, RAW 264.7 macrophages, Anti-inflammation, NF-kB, MAPKs

\section{Background}

Nuclear factor kappa B (NF- $\kappa \mathrm{B})$ is a protein complex, involved in the transcription of number of genes related to the production of pro-inflammatory cytokines and has also been demonstrated to play central role in the LPS-induced expression of iNOS and cyclooxygenase-2 (COX2) from different cells (Merchant et al. 2017; Mulgund et al. 2015). Under the normal conditions, $\mathrm{NF}-\mathrm{kB}$ exists in the cytoplasm as an inactive dimer protein complex. However, upon the activation, NF- $\mathrm{kB}$ proteins undergo the phosphorylation and translocation to the nucleus. The translocated NF- $\mathrm{kB}$ heterodimers ( $\mathrm{p} 50$

\footnotetext{
* Correspondence: yhjee@jejunu.ac.kr; youjinj@jejunu.ac.kr

${ }^{5}$ Department of Veterinary Medicine and Veterinary Medical Research

Institute, Jeju National University, Jeju 63243, Republic of Korea

${ }^{1}$ Department of Marine Life Science, School of Marine Biomedical Sciences,

Jeju National University, Jeju 63243, Republic of Korea

Full list of author information is available at the end of the article
}

and RelA; p65) then binds to promoter regions responsible for the transcription of genes that encode for pro-inflammatory cytokines, chemokines, and other proteins related to the production of proteins such as iNOS and COX2 (Pugh et al. 2012). Therefore, it has been suggested that inhibition of NF- $\mathrm{kB}$ activity including activation and translocation might help to reduce inflammation related complications.

Sargassum horneri (Sargassaceae, Fucales, Phaeophyta) is an edible brown seaweed, abundant worldwide in shallow sea-water ecosystems (Herath et al. 2019; Kim et al. 2018). The thallus of $S$. horneri is large, macroscopic, and brown-colored, and its stem is cylindrical, erect, and flat. Young seaweeds resemble ferns, with opposite leaf-like blades, extending from a central axis. The blades have broad, deeply incised, and ragged tips. As

(c) The Author(s). 2019 Open Access This article is distributed under the terms of the Creative Commons Attribution 4.0 International License (http://creativecommons.org/licenses/by/4.0/), which permits unrestricted use, distribution, and 
the plant grows, it becomes a single frond, loosely branched, in a zig-zag pattern (Huang et al. 2017; Xie et al. 2014). Once it matures, the blades become narrower and the branches develop small, ellipsoidal air bladders and larger spindle-shaped reproductive receptacles, both on stalks (Kubo et al. 2017). Apart from the ecological importance, S. horneri is popular as a nutrient-rich edible seaweed in the East Asian countries. Side dishes or soup prepared by mixing $S$. horneri thallus with meat or fish are popular in the countries located in the East Asia region. In Japan, S. horneri is known as "akamoku" and is harvested at the maturation stage for eating in regions along the East Sea (Nomura et al. 2012; Ma et al. 2014).

To select one of the extraction methods to prepare extracts containing bioactive compounds from seaweeds is an important step which has a great impact on the research outcomes. However, the selection of the suitable extraction method depends on the target compounds and its applications (da Silva et al. 2016). The industrial level applications such as functional foods and nutraceuticals require large amount of active substrates at low production cost (Fleurence 1999). However, isolation of active compounds for industrial level applications from seaweeds is limited due to the time-consuming operations and availability of skilled labors for isolation processes. Thus, crude extracts from seaweeds as an active ingredient are more popular over the pure compounds industries like functional foods (Kadam and Prabhasankar 2010). Taken together, in the present study, anti-inflammatory properties of the ethanolic extract obtained from S. horneri, with industrial-scale production by the company, Seojin Biotech, were evaluated on LPS-activated RAW 264.7 macrophages.

\section{Material and methods}

\section{Regents and antibodies}

All reagents used this study were purchased from Sigma-Aldrich (St. Louis, MO, USA) unless stated otherwise. Enzyme-linked immunosorbent assay (ELISA) kits for mouse IL-1 $\beta$, IL-6, and TNF- $\alpha$ were purchased from R\&D Systems (Minneapolis, MN, USA). Antibodies against iNOS, COX2, p50, p-p50, p65, p-p65, $\beta$-actin, nucleolin, ERK 1/2, p-ERK 1/2, JNK, and p-JNK were purchased from cell signaling Technology (Beverly, MA, USA). Prime Script ${ }^{\mathrm{ma}}$ first-strand cDNA synthesis kit for cDNA synthesis and ExTaq ${ }^{\text {Tm }}$ SYBR premix were purchased from TaKaRa, Japan. Dulbecco's Modified Eagle Medium (DMEM), fetal bovine serum (FBS), and penicillin-streptomycin $(10,000 \mathrm{U} / \mathrm{ml})$ were purchased from Life Technologies Corporation, Grand Island, NY, USA. The primers for amplification against iNOS, COX2, IL-1 $\beta$, IL-6, and TNF- $\alpha$ were purchased from Bioneer, Seoul, South Korea.

\section{Preparation of the ethanol extracts from S. horneri and composition analysis}

Seventy percent ethanol extract of S. horneri collected along the shores of Jeju Island were kindly prepared and provided by Seojin Biotech Co. Ltd., Korea (lot number SJFC70180625) (SJB-SHE). Briefly, the air-dried $\left(50^{\circ} \mathrm{C}\right)$ seaweed samples were ground and passed through a 40-50 mesh by Pin-mill. Then, $100 \mathrm{~g}$ of powdered $S$. horneri was extracted with $70 \%$ ethanol solution at $65-80^{\circ} \mathrm{C}$ for $12 \mathrm{~h}$. Then, the extractants were concentrated and freeze-dried to obtain 70\% ethanolic extract of S. horneri. Then, the resulted powder again dissolved in the $100 \%$ ethanol solution for $2 \mathrm{~h}$ with cellulose and then centrifuged at $12,000 \mathrm{rpm}$ in room temperature to remove remaining residues and heavy metals. The supernatant was concentrated and treated with $95 \% \mathrm{EtOH}$ to increase purity (Herath et al. 2019). The resultant powder (SJB-SHE) was used to the consequent studies mentioned in this study. Details procedures of sample preparation, composition analysis, and composition data of SJB-SHE were similar to Herath et al. (2019).

\section{Cell culture and cell viability assay}

RAW 264.7 murine macrophages were purchased from the American Type Culture Collection, Manassas, VA, USA. The macrophages were maintained at $37^{\circ} \mathrm{C}, 5 \% \mathrm{CO}_{2}$ in DMEM media supplemented with $10 \%$ heat-inactivated FBS, and $1 \%$ antibiotics. The cells were sub-cultured within $48 \mathrm{~h}$ intervals. The LDH activity in the culture mediums was assessed using LDH cytotoxicity detection kit (Promega, Madison, WI, USA) by following the vendor's instructions. The effect of SJB-SHE on cell viability was examined by colorimetric MTT assay similar to the previously described method (Jayawardena et al. 2018). The LDH release and cell viability were calculated as shown below using plate reader at $490 \mathrm{~nm}$ and $540 \mathrm{~nm}$ respectively.

\section{Determination of $\mathrm{NO}, \mathrm{PGE}_{2}$, and cytokine production (TNF- $\alpha$, IL-1 $\beta$, and IL-6)}

RAW 264.7 macrophages were incubated with various concentration of SJB-SHE $(62.5 \sim 250 \mu \mathrm{g} / \mathrm{ml})$ and LPS $(1 \mu \mathrm{g} / \mathrm{ml})$ for $24 \mathrm{~h}$. The NO production in the culture medium was quantified by Griess reagent as following a previously established method (Jayawardena et al. 2018). The level of PGE 2 , TNF- $\alpha$, IL-1 $\beta$, and IL- 6 in culture supernatants were evaluated using ELISA kit according to the manufacturer's instructions.

\section{Western blot analysis}

Whole-cell protein lysates and nucleus proteins were extracted using NE-PER ${ }^{\circ}$ Nuclear and Cytoplasmic Extraction Kit (Thermo Scientific, Rockford, USA) following a method described by Sanjeewa et al. (2017). 
Equal amounts $(40 \mu \mathrm{g})$ of protein were electrophoresed in $12 \%$ SDS-PAGE. After blocking with 05\% non-fat milk for $60 \mathrm{~min}$, the blots were separately incubated with the following primary antibodies: rabbit polyclonal antibodies including iNOS, ERK1/2 (extracellular signal-regulated kinase), p-ERK1/2, JNK, p-JNK, NF-кB p65, NF-кB p50, с-23, COX2, and $\beta$-actin (Cell Signaling Technology, Beverly, MA, USA) overnight. The blots were washed twice with Tween 20/Tris-buffered saline (TTBS) and then incubated with HRP-conjugated anti-rabbit IgG for $30 \mathrm{~min}$. Antibody binding was visualized by using an enhanced chemiluminescent substrate (Cyanagen Srl, Bologna, Italy). The basal level of each protein was normalized by analyzing the level of $\beta$-actin or c-23. Membranes were photographed using a FUSION SOLO Vilber Lourmat system. The intensities of bands were quantified using the ImageJ (version 1.4) program (Sanjeewa et al. 2017).

\section{RNA extraction and quantitative reverse transcription-polymerase chain reaction (qRT-PCR)}

Total RNA was isolated with Trizol reagent according to the manufacturer's instruction. Total RNA $(1 \mu \mathrm{g})$ was reverse-transcribed to produce cDNA using a first-strand cDNA Synthesis Kit according to the manufacturer's instructions. The target cDNA was amplified using the primers as provided in Table 1. All relative gene expression quantifications were normalized to GAPDH as an internal control.

\section{Statistical analysis}

All the results are expressed as the mean values with the standard deviation of three independent repetitions. Statistical significance was determined using $t$ test and one-way or two-way analysis of variance (ANOVA) followed by Dunnett's post hoc test using IBM $^{\circ}$ SPSS $^{\circ}$ statistics (Version 20) software. Significant differences were assigned to $P$ values $<0.05$ and $<0.01$ denoted by * or \# and $*$ or \#\# respectively.

\section{Results}

Proximate composition of seaweed extract (SJB-SHE)

According to the chemical composition results, SJB-SHE is mainly composed of polyphenols $(15.30 \pm 0.01 \%)$,

Table 1 Sequence of the primers used in this study

\begin{tabular}{lll}
\hline Gene & Primer & Sequence from $5^{\prime} \rightarrow 3^{\prime}$ \\
\hline GAPDH & Sense & AAGGGTCATCATCTCTGCCC \\
& Antisense & GTGATGGCATGGACTGTGGT- \\
iNOS & Sense & ATGTCCGAAGCAAACATCAC \\
& Antisense & TAATGTCCAGGAAGTAGGTG \\
COX2 & Sense & CAGCAAATCCTTGCTGTTCC \\
& Antisense & TGGGCAAAGAATGCAAACATC \\
\hline
\end{tabular}

carbohydrate $(39.99 \pm 0.54 \%)$, and proteins $(16.84 \pm 0.74 \%)$. Additionally, SJB-SHE contains considerable amounts of ash $(28.39 \pm 0.51 \%)$ and moisture $(14.68 \pm 0.21)$. The flavonoid and lipid contents observed in the SJB-SHE are less than $1 \%$.

\section{Effect of SJB-SHE on cell viability and LPS-induced NO and $\mathrm{PGE}_{2}$ production}

A range of concentrations $(31.2 \sim 2000 \mu \mathrm{g} / \mathrm{ml})$ was prepared from SJB-SHE to determine the safe concentrations to treat RAW 264.7 macrophages. As shown in Fig. 1a and $\mathrm{b}$, the concentrations between $31.2 \sim 250 \mu \mathrm{g} / \mathrm{ml}$ did not express any cytotoxic effect towards the RAW 264.7 macrophages. Therefore, as the next part of the study, the protective effect of SJB-SHE was evaluated against LPS-induced toxicity and NO production in RAW 264.7 macrophages. According to the results, the treatment of LPS significantly increased the cell death rates and NO production. However, the treatment of SJB-SHE significantly and dose-dependently reduced the LPS-induced toxicity (Fig. 1c) and NO production (Fig. 1d). In addition to $\mathrm{NO}, \mathrm{PGE}_{2}$ was also identified as an inflammatory mediator produced by the macrophages which leads to the activation of inflammatory reactions. In the present study, thus, the levels of $\mathrm{PGE}_{2}$ in the culture supernatants were quantified by using the ELISA kit (Fig. 2a). The level of $\mathrm{PGE}_{2}$ was significantly increased with the treatment of LPS. However, SJB-SHE dose-dependently reduced the LPS-induced $\mathrm{PGE}_{2}$ production in the activated macrophages.

\section{Protective effect of SJB-SHE against LPS-induced pro-inflammatory cytokine production}

To evaluate the pro-inflammatory cytokine inhibitory effect of SJB-SHE (TNF- $\alpha$, IL-1 $\beta$, and IL-6), macrophages were incubated with SJB-SHE $(62.5,125$, and $250 \mu \mathrm{g} / \mathrm{ml})$ in the presence or absence of LPS $(1 \mu \mathrm{g} / \mathrm{ml})$ for $24 \mathrm{~h}$, and the pro-inflammatory cytokine levels in the culture supernatants were measured by ELISA. It was noted that the treatment of SJB-SHE dose-dependently inhibited the LPS-activated TNF- $\alpha$ (Fig. $2 b$ ), IL-1 $\beta$ (Fig. 2c), and IL-6 (Fig. 2d) secretion from macrophages. Specifically, the treatment of SJB-SHE strongly suppressed the IL-1 $\beta$ production from LPS-activated macrophages, and at the $250 \mu \mathrm{g} / \mathrm{ml}$ concentration, SJB-SHE inhibited more than $90 \%$ IL-1 $\beta$ compared to the LPS-treated group.

\section{SJB-SHE attenuate LPS-induced iNOS and COX2 secretion from LPS-activated macrophages}

To identify the mechanism how SJB-SHE reduces LPS-activated $\mathrm{NO}$ and $\mathrm{PGE}_{2}$ production, the inhibitory effect of SJB-SHE $(62.5,125$, and $250 \mu \mathrm{g} / \mathrm{ml})$ against LPS-activated iNOS and COX2 protein and its gene expression (Fig. 3) were evaluated. 


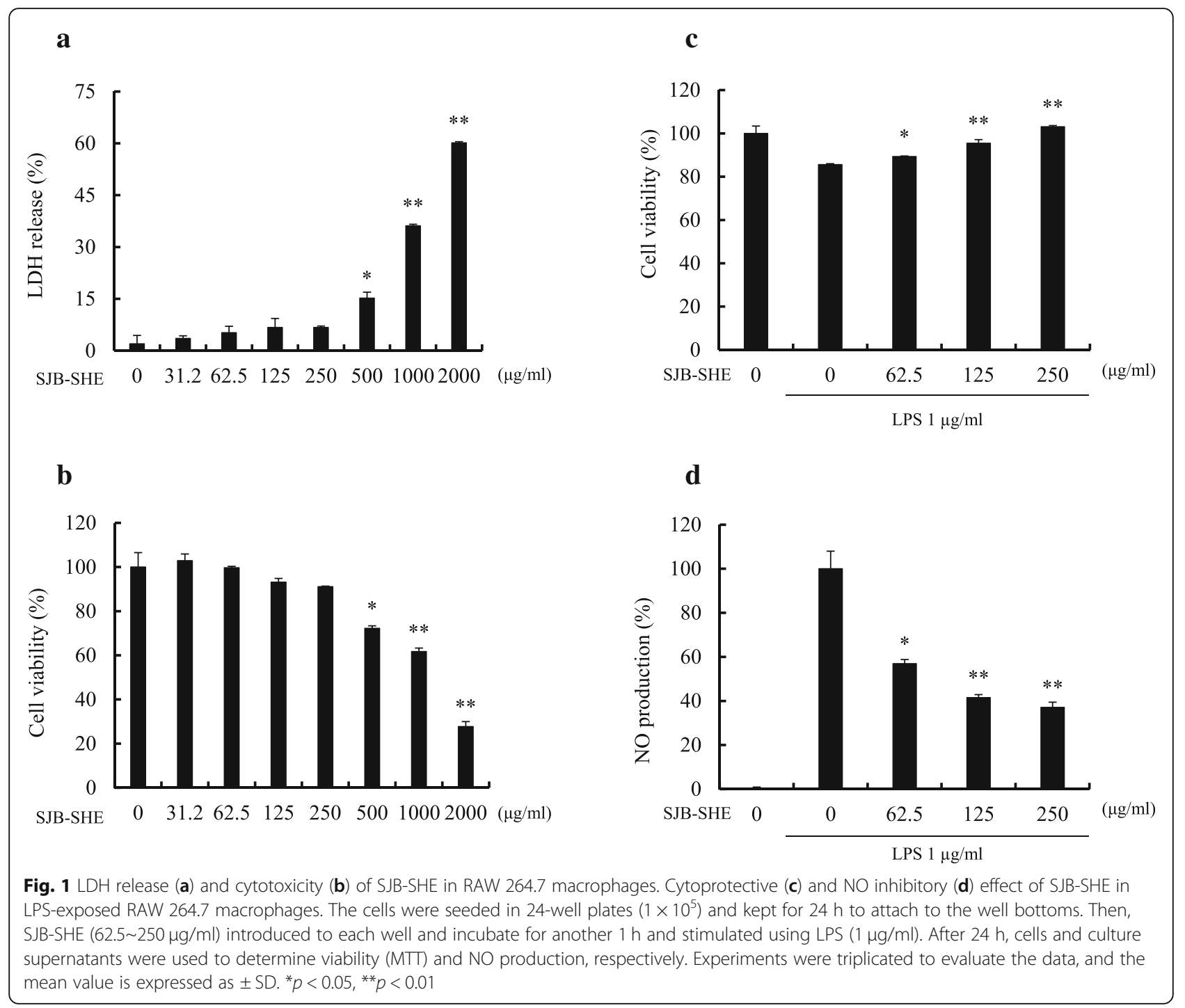

As shown in Fig. 3a, the Western blot analysis was performed to evaluate the effect of SJB-SHE on COX2 and iNOS protein production. According to the results, the LPS-treated macrophages $(1 \mu \mathrm{g} / \mathrm{ml})$ had elevated levels of COX2 and iNOS (Fig. 3a and Fig. 3b) protein production compared to the untreated control. However, with the treatment of SJBSHE, the elevated levels of COX2 (Fig. 3c) and iNOS (Fig. 3d) were significantly reduced. In addition to the Western blot analysis, the effect of SJB-SHE on the expression of iNOS and COX2 mRNA level was quantified using RT-qPCR analysis. According to the results, mRNA expression levels of COX2 and iNOS were similar to the Western blot results. These results strongly suggest the potential of SJB-SHE to more suppress COX2 than iNOS.

\section{SJB-SHE attenuate LPS-induced NF-KB activation and} translocation

To investigate whether SJB-SHE $(62.5 \sim 250 \mu \mathrm{g} / \mathrm{ml})$ could affect activation and nuclear translocation of NF- $\mathrm{KB}$, Western blot analysis for NF- $\mathrm{kB}$ p65, NF- $\mathrm{kB}$ p50, and their phosphorylated forms was carried out with cytosolic and nuclear extracts of LPS-stimulated RAW 264.7 macrophages (Fig. 4). The relative expression of phosphorylated forms, NF-kB p50 and p65, in the cytosol were markedly increased upon the exposure of LPS. However, SJB-SHE inhibited LPS-mediated NF- $\kappa B$ phosphorylation in the cytosol (Fig. 4a and Fig. 4b). Additionally, to determine whether SJB-SHE was associated with the nucleus translocation of NF- $\mathrm{kB}$, the levels of $\mathrm{p} 50$ and p65 in the nucleus were examined. According to the results, LPS was demonstrated to upregulate the 

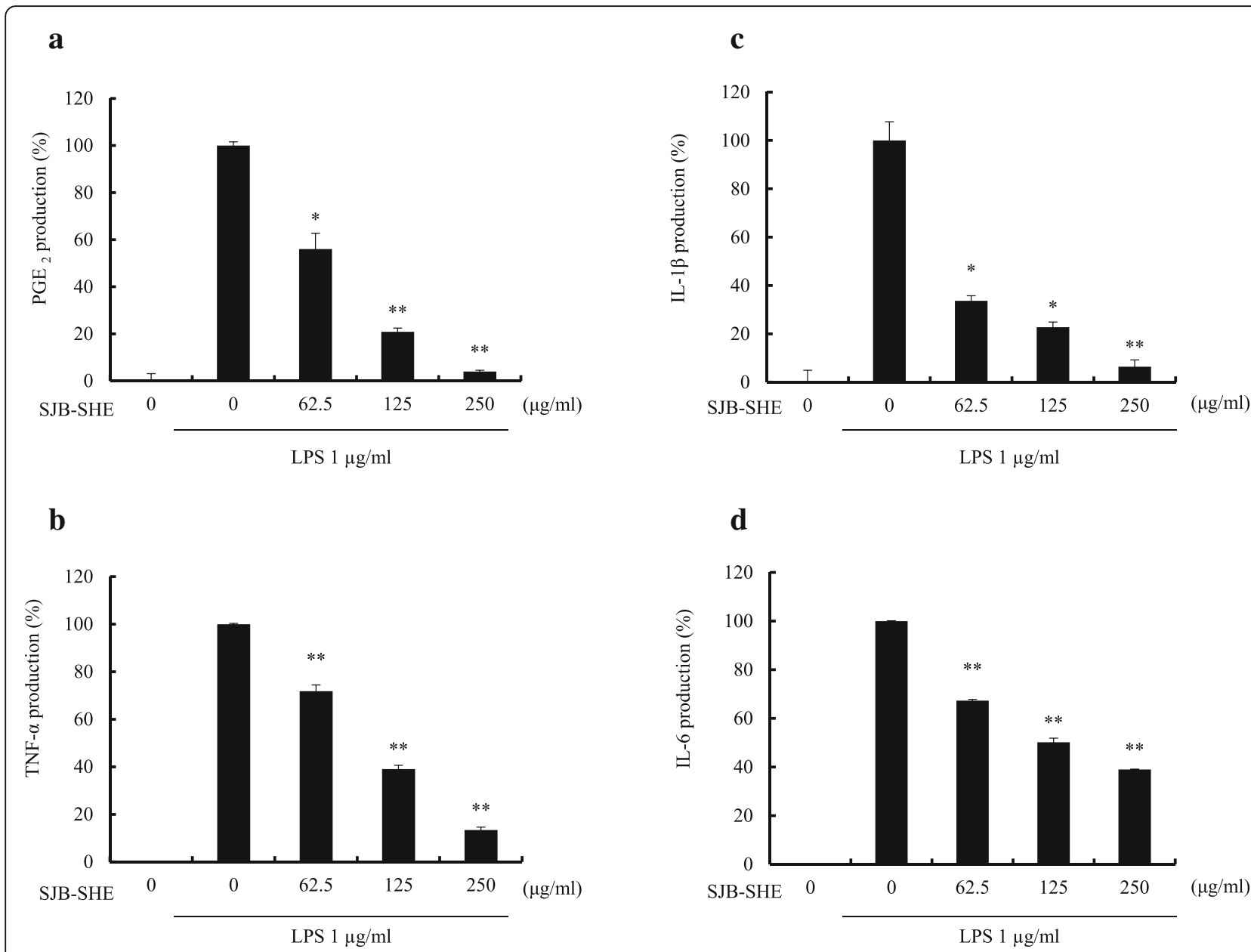

Fig. 2 Inhibitory effect of SJB-SHE on the PGE 2 (a) and pro-inflammatory cytokines including TNF- $a(\mathbf{b}) \mathrm{IL}-1 \beta$ (c), and IL-6 (d) production in LPSinduced RAW 264.7 macrophages. Experiments were conducted using ELISA. SJB-SHE- $(62.5 \sim 250 \mu \mathrm{g} / \mathrm{ml})$ and LPS $(1 \mu \mathrm{g} / \mathrm{ml})$ treated cell supernatants were collected to quantify the inflammatory cytokines and $\mathrm{PGE}_{2}$. Experiments were triplicated to evaluate the data, and the mean value is expressed as \pm SD. ${ }^{*} p<0.05$ and ${ }^{* *} p<0.01$

translocation of p50 and p65 from the cytosol to the nucleus after $30 \mathrm{~min}$ of LPS stimulation (Fig. 4c), and SJB-SHE remarkably downregulated them (Fig. 4d). These results suggest that the treatment of SJB-SHE has a potential to inhibit the LPS-induced NF- $\kappa B$ activation and translocation to the nucleus.

\section{SJB-SHE inhibit LPS-induced MAPK phosphorylation}

In an attempt to identify whether or not the inhibition of inflammatory responses demonstrated by SJB-SHE is mediated via the mitogen-activated protein kinases (MAPK) pathway, the inhibitory effects of SJB-SHE were observed on LPS-induced phosphorylation of growth factor-regulated extracellular signal-related kinases (ERK) $1 / 2$ and c-jun N-terminal kinases (JNK) proteins in RAW 264.7 macrophages via Western blotting. As presented in Fig. 5, LPS $(1 \mu \mathrm{g} / \mathrm{ml})$ significantly upregulated the phosphorylation of ERK $1 / 2$ and JNK in RAW 264.7 macrophages. However, SJB-SHE $(62.5,125$, and
$250 \mu \mathrm{g} / \mathrm{ml}$ ) treatments sufficiently reduced the phosphorylation of ERK1/2 and JNK in LPS-activated macrophages.

\section{Discussion}

In the present study, we demonstrated the anti-inflammatory potential of 70\% ethanol extract obtained from S. horneri against LPS-activated macrophages. The extraction procedure was carried out in commercial scale by Seojin Biotech Co. Ltd., Korea. According to the results, SJB-SHE $(62.5 \sim 250 \mu \mathrm{g} / \mathrm{ml})$ inhibited the LPS-induced $(1 \mu \mathrm{g} / \mathrm{ml}) \mathrm{NO}, \mathrm{PGE}_{2}$, and pro-inflammatory cytokine production via blocking the activation and translocation of NF- $\mathrm{KB}$ proteins as well as inhibiting the MAPKs phosphorylation.

A large number of phlorotannin substances, particularly those present in brown seaweeds, have been reported to possess a number of bioactive properties including anti-inflammation, antioxidant, and anticancer 


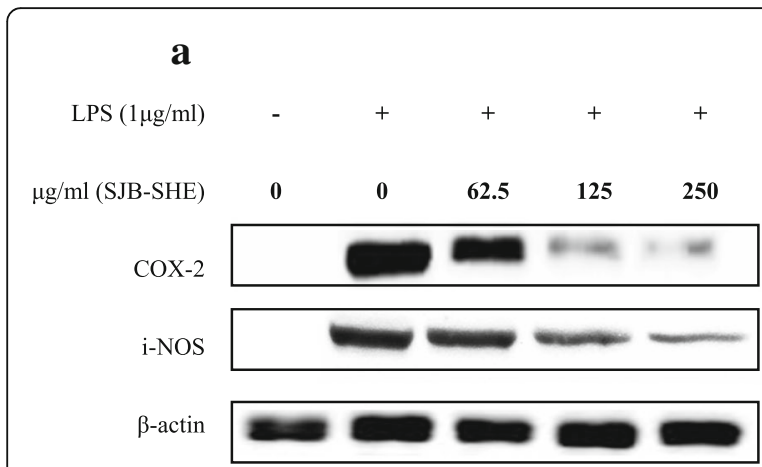

b

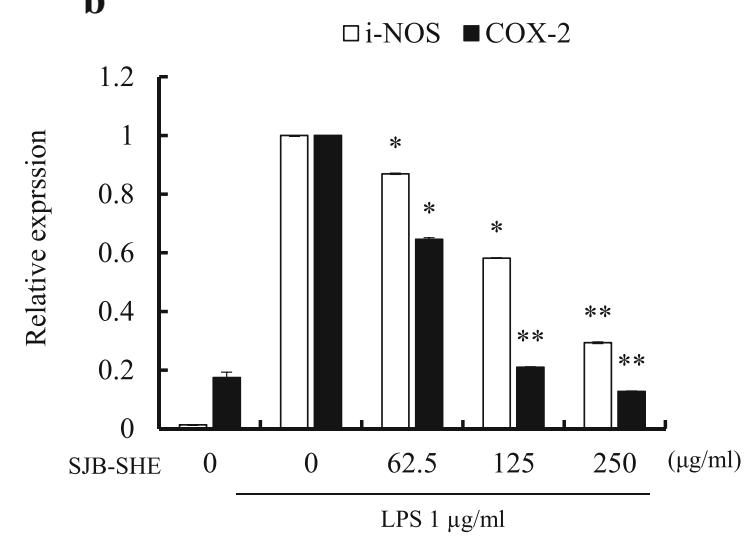

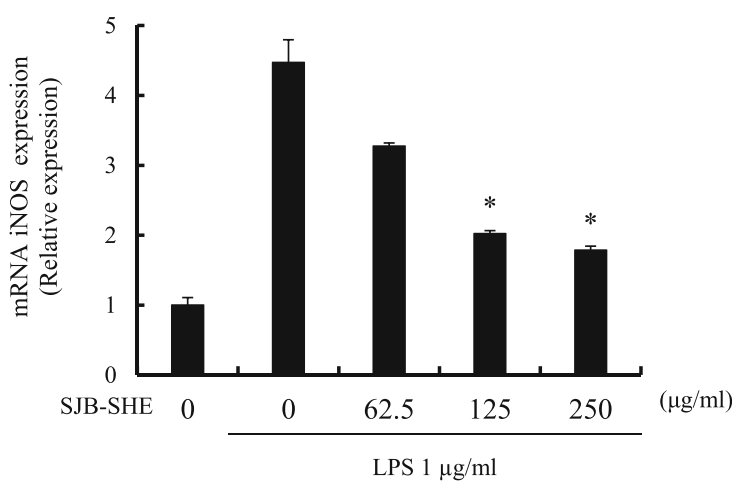

d

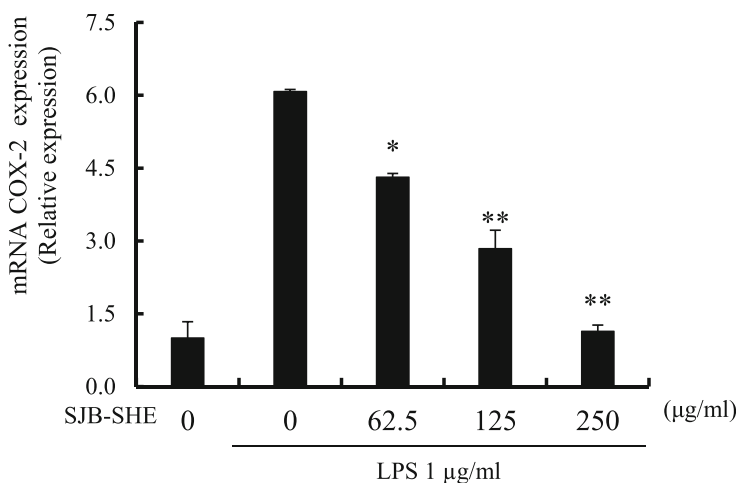

Fig. 3 Inhibitory effects of SJB-SHE on LPS-induced inflammation-associated protein in RAW 264.7 macrophages. Western blots used to determine iNOS and COX2 levels (a), the related expression of the bands were analyzed using ImageJ software (b). $\beta$-actin was used as internal control. Results are expressed as the mean \pm SD of three separate experiments. The gene expression analysis of iNOS (c) and COX2 (d). The $2^{-\Delta \Delta C t}$ method was used to calculate the relative mRNA levels. Internal reference used in the experiment was GAPDH. Experiments were triplicated. mRNA significance relative to the non-treated control was calculated using the Mann-Whitney $U$ test. ${ }^{*} p<0.05$ and ${ }^{* *} p<0.01$

(Wijesinghe and Jeon 2011). However, the use of pure compounds for functional foods and other applications in large quantities are not cost-effective and require time-consuming operations to isolate bio-active natural substances. Therefore, in the present study, we attempted to evaluate anti-inflammatory mechanisms of a commercial scale extract of S. horneri (SJB-SHE) using LPS-activated RAW 264.7 macrophages. COX2 and iNOS are important inflammatory mediators which are responsible for initiating inflammation in cellular environments. $\mathrm{NO}$ and $\mathrm{PGE}_{2}$ are produced by two different proteins namely iNOS and COX2, respectively (Hseu et al. 2005). It has been reported that uncontrolled/irregular upregulated production of iNOS and COX2 has been associated with the pathophysiology of cancers and inflammatory disorders (Surh et al. 2001). Thus, the extracts capable to inhibit iNOS and COX2 might have the potential to reduce inflammatory responses and act as functional materials. Therefore, in the present study, we attempted to evaluate iNOS and COX2 inhibitory effect of SJB-SHE using LPS-activated RAW 264.7 macrophages. According to the results, treatments of SJB-SHE cause to downregulate iNOS and COX2 levels observed in LPS-activated macrophage cells (protein and mRNA). This result suggests that SJB-SHE has a potential to inhibit $\mathrm{NO}$ and $\mathrm{PGE}_{2}$ via downregulating $\mathrm{iNOS}$ and $\mathrm{COX} 2$ expression in LPS-activated RAW 264.7 macrophages.

The initiation and development of the inflammation process involve a series of pro-inflammatory cytokines. LPS is a well-known immune stimulant used to activate macrophage and production of cytokine is a major response. Based on the previous studies, the inhibition of pro-inflammatory cytokines (TNF- $\alpha$, IL- $1 \beta$, and IL-6) provide solid insights to develop functional products against inflammatory responses ( $\mathrm{Li}$ et al. 2018). According to the results we noted, the treatment of SJB-SHE has a potential to inhibit LPS-activated inflammation in RAW 264.7 macrophages by suppressing 


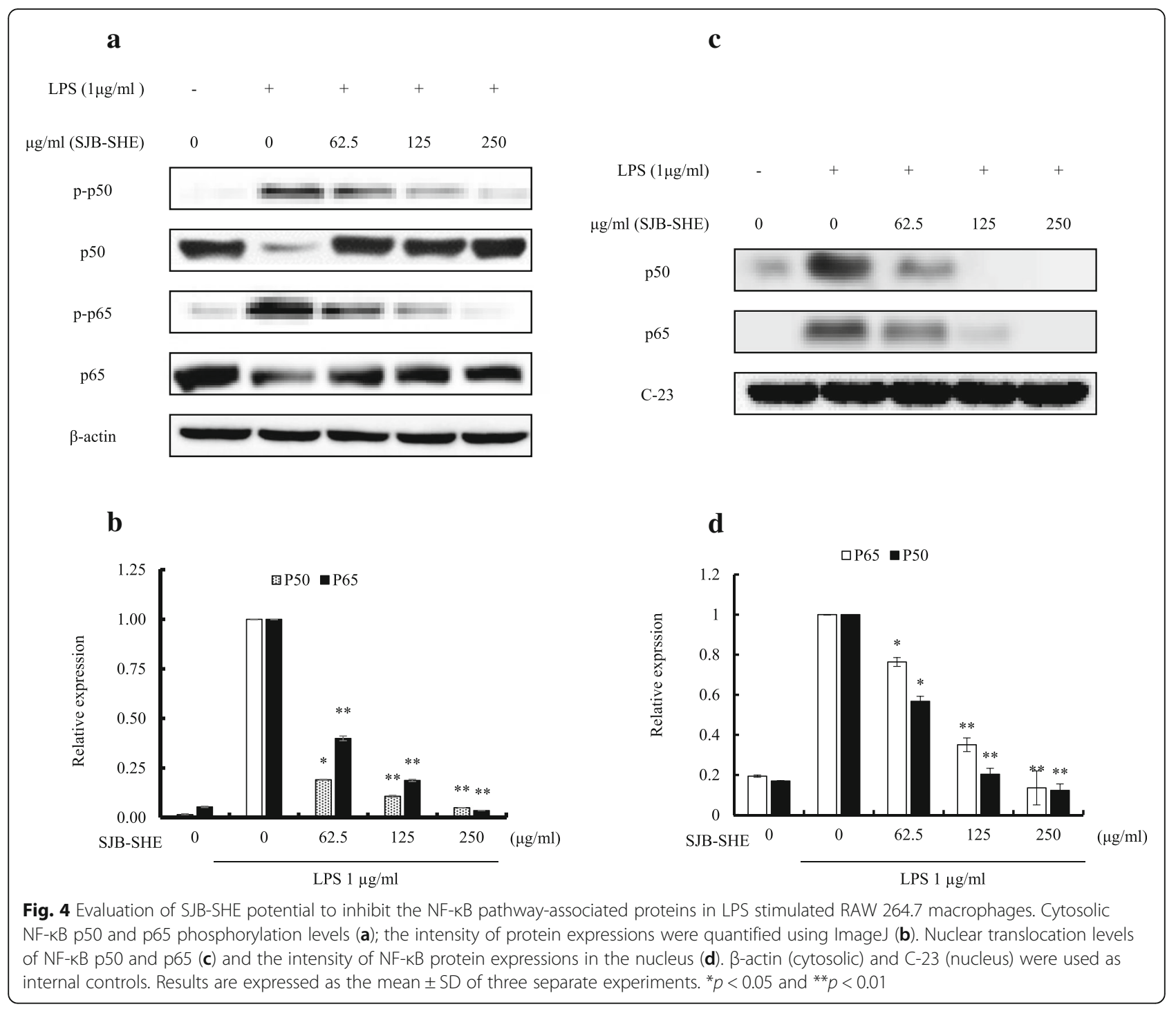

cytokine secretion. In addition to this study, Sanjeewa et al. (2017) reported that the crude polysaccharide separated from $S$. horneri has a potential to inhibit LPS-activated pro-inflammatory cytokine secretion from RAW 264.7 macrophages.

NF- $\kappa B$ comprises a family (Rel) of transcriptional factors, upon activation form heterodimers and homodimers, binds to target DNA promoter sequences, and then triggers gene expression. Under the normal conditions, NF- $\mathrm{kB}$ proteins (p50 and p65) bind with an inhibitor, namely $\mathrm{I} \kappa B \alpha$, and remain in the cytoplasm in an inactive state. However, when cells exposed to the inflammatory stimuli such as LPS, I $\mathrm{B} \alpha \alpha$ degrades and NF- $\mathrm{KB}$ translocates to the nucleus and lead to transcription of inflammation-related genes (Lund 2010). Moreover, regulation of inflammatory mediators such as iNOS, COX2, and pro-inflammatory cytokines is known to occur primarily on the transcriptional level, whereby activate the levels of transcription factor NF- $k B$ (Kiemer et al. 2003). Other than iNOS and COX2, Zielinski and Krueger (2012) reported the activation of NF-kB also causes to activate pro-inflammatory cytokine (IL-1 $\beta$ and TNF- $\alpha$ ) expression and inhibits anti-inflammatory cytokines (IL-4 and IL-10) (Zielinski and Krueger 2012). Previously, a number of studies reported that organic extracts obtained from brown seaweeds have the potential to inhibit LPS-induced NF-KB activation and translocation them to the nucleus in macrophages (Kim et al. 2009; Jung et al. 2013). Similarly, we also noted the treatment of different concentrations of SJB-SHE causes to downregulate the LPS-activated NF- $\mathrm{kB}$ activation and translocation.

MAPKs, the serine-threonine protein kinases, regulate cellular activities by mediating the signal transduction from cell surface to nucleus to initiate gene expression, mitosis, differentiation, survival, and apoptosis (Salter 2015). A number of studies reported that MAPKs play an important 
$\mathbf{a}$

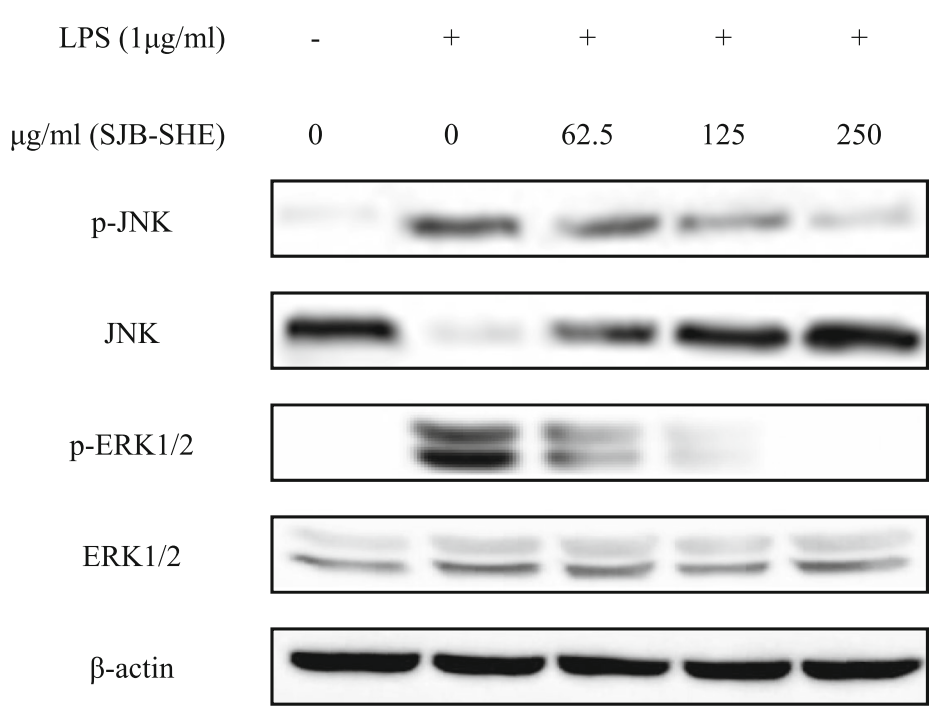

b

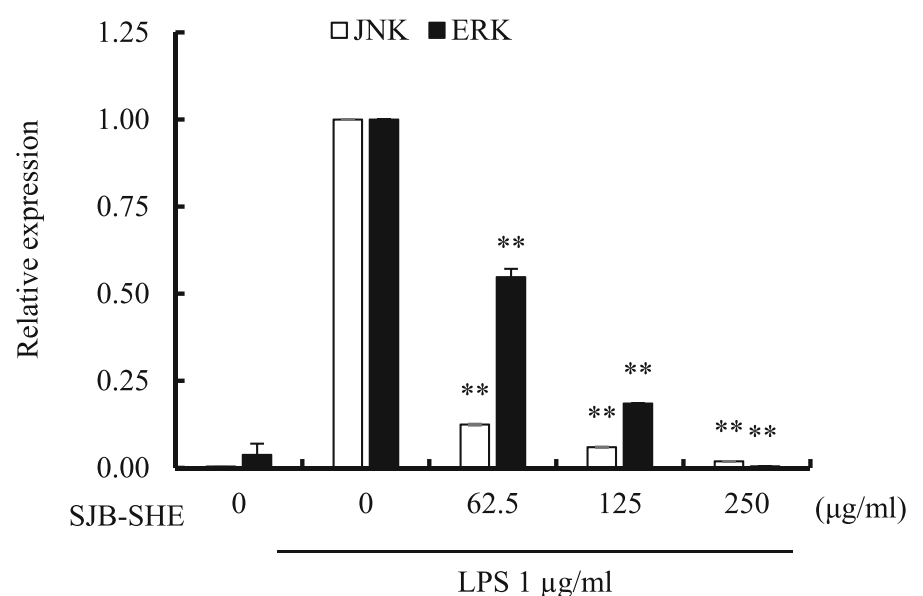

Fig. 5 MAPK pathway-associated protein evaluation in LPS-induced RAW 264.7 macrophages. The inhibitory effect SJB-SHE against LPS-activated MAPK phosphorylation evaluated using Western blot (a) and obtained quantitative data (b). $\beta$-actin was used as the internal standard. Image J ( $V$ 1.4) was used to analyze the band intensities and quantify the data. Results are expressed as the mean \pm SD of three separate experiments. ${ }^{*} p<0.05$ and ${ }^{* *} p<0.01$

role during inflammation by activating gene expressions of pro-inflammatory cytokines and chemokines (Akira 2001). According to the previous studies, MAPKs such as ERK1/2 and JNK are activated by LPS stimulation (Akira 2001). Taken together, the inhibition of MAPKs phosphorylation is a feasible approach to treat inflammatory diseases (Li et al. 2018). In order to identify the effect of SJB-SHE on MAPK inhibition, the phosphorylation levels of ERK1/2 and JNK were evaluated using Western blot analysis. In the present study, we also demonstrated the treatment of LPS $(1 \mu \mathrm{g} / \mathrm{ml})$ causes to upregulate the MAPKs phosphorylation significantly compared to the control. However, the upregulated phosphorylation levels of ERK1/2 and JNK were downregulated by SJB-SHE at the tested concentrations $(62.5 \sim 250 \mu \mathrm{g} / \mathrm{ml})$. The inhibitory effect of SJB-SHE against LPS-activated MAPKs phosphorylation might be associated with its anti-inflammatory activity.

\section{Conclusions}

According to the results, SJB-SHE abate the LPS-activated $\mathrm{NO}, \mathrm{PGE}_{2}$, and pro-inflammatory cytokine production from RAW 264.7 macrophages. Subsequent studies demonstrated the inhibitory effect of SJB-SHE against LPS-activated NF- $\kappa B$ activation and translocation 
to the nucleus as well as its inhibitory effect of MAPKs phosphorylation. Taken together, our findings provided a clear insight into the molecular mechanisms by which SJB-SHE inhibited the inflammation through suppressing NF- $\mathrm{kB}$ and MAPK signaling pathways in RAW 264.7 macrophages. Therefore, this study might be useful to develop functional material from $S$. horneri in the future at a low cost.

\section{Abbreviations}

DMEM: Dulbecco's Modified Eagle Medium; ERK: Extracellular signal-related kinases; FBS: Fetal bovine serum;

JNK: c-jun N-terminal kinases; MAPK: Mitogen-activated protein kinases; MTT: 3-(4,5-Dimethylthiazol-2-yl)-2, 5-diphenyltetrazolium bromide; NF-kB: Nuclear factor kappa B; SJB-SHE: 70\% ethanol extract of S. horneri provided by Seojin Biotech Co. Ltd., Korea

\section{Acknowledgements}

The authors wish to thanks National Research Foundation of Korea and the Ministry of Education to support for this study.

\section{Funding}

The research was supported by the Program of National Research

Foundation of Korea through the Ministry of Education.

\section{Availability of data and materials}

All data sets generated and/or analyzed during the current study are available from the corresponding author on reasonable request.

\section{Authors' contributions}

KKAS, YJ, and YJJ designed this study, drafted the manuscript, and revised the manuscript. KKAS, HSK, SYK, GA, HJK, and TUJ performed the experiments, analyzed the data, and drafted the manuscript. KKAS, YJ, TUJ, SYK, and XF conceived the study. All authors read and approved the final manuscript.

\section{Ethics approval and consent to participate}

Not applicable.

\section{Consent for publication}

Not applicable.

\section{Competing interests}

The authors declare that they have no competing interests.

\section{Publisher's Note}

Springer Nature remains neutral with regard to jurisdictional claims in published maps and institutional affiliations.

\begin{abstract}
Author details
'Department of Marine Life Science, School of Marine Biomedical Sciences, Jeju National University, Jeju 63243, Republic of Korea. ${ }^{2}$ Department of Food Technology and Nutrition, Chonnam National University, Yeosu 59626, Republic of Korea. ${ }^{3}$ Seojin Biotech Co. Ltd, Acedongbaek Tower, 1-501 504, 16-4, Dongbaekjungang-ro, 16 beon-gil, Gieung-gu, Yongin-si, Gyeonggi-do 17015, Republic of Korea. ${ }^{4}$ College of Food Science and Engineering, Ocean University of China, Qingdao 266003, Shandong, China. ${ }^{5}$ Department of Veterinary Medicine and Veterinary Medical Research Institute, Jeju National University, Jeju 63243, Republic of Korea.
\end{abstract}

Received: 18 January 2019 Accepted: 6 February 2019

Published online: 27 February 2019

\section{References}

Akira S. Toll-like receptors and innate immunity. In: Dixon FJ, editor. Advances in immunology, vol 78. United States: Academic Press; 2001. p. 1-56. ISSN 00652776, ISBN 9780120224784, https://doi.org/10.1016/S0065-2776(01)78001-7, (http://www.sciencedirect.com/science/article/pii/S0065277601780017). da Silva RPFF, Rocha-Santos TAP, Duarte AC. Supercritical fluid extraction of bioactive compounds. TrAC Trends Anal Chem. 2016:76:40-51.

Fleurence J. Seaweed proteins: biochemical, nutritional aspects and potential uses. Trends Food Sci Technol. 1999:10:25-8.

Herath K, Cho J, Kim A, Kim HS, Han EJ, Kim HJ, Kim MS, Ahn G, Jeon YJ, Jee Y. Differential modulation of immune response and cytokine profiles of Sargassum horneri ethanol extract in murine spleen with or without Concanavalin A stimulation. Biomed Pharmacother. 2019;110:930-42.

Hseu YC, Wu FY, Wu JJ, Chen JY, Chang WH, Lu FJ, Lai YC, Yang HL. Anti inflammatory potential of Antrodia Camphorata through inhibition of iNOS, COX-2 and cytokines via the NF-kappaB pathway. Int Immunopharmacol. 2005:5:1914-25.

Huang C, Sun Z, Gao D, Yao J, Hu Z, Li Y, Wang Y, Xu K, Chen W. Molecular analysis of Sargassum from the northern China seas. Phytotaxa. 2017;319:71-83.

Jayawardena TU, Asanka Sanjeewa KK, Shanura Fernando IP, Ryu BM, Kang M-C, Jee $Y$, Lee WW, Jeon Y-J. Sargassum horneri (Turner) C. Agardh ethanol extract inhibits the fine dust inflammation response via activating $\mathrm{Nrf2} / \mathrm{HO}-1$ signaling in RAW 264.7 cells. BMC Complement Altern Med. 2018;18:249.

Jung HA, Jin SE, Ahn BR, Lee CM, Choi JS. Anti-inflammatory activity of edible brown alga Eisenia bicyclis and its constituents fucosterol and phlorotannins in LPSstimulated RAW264.7 macrophages. Food Chem Toxicol. 2013;59:199-206.

Kadam SU, Prabhasankar P. Marine foods as functional ingredients in bakery and pasta products. Food Res Int. 2010;43:1975-80.

Kiemer AK, Hartung T, Huber C, Vollmar AM. Phyllanthus amarus has anti-inflammatory potential by inhibition of iNOS, COX-2, and cytokines via the NF-KB pathway. J Hepatol. 2003;38:289-97.

Kim H-S, Sanjeewa KKA, Fernando IPS, Ryu B, Yang H-W, Ahn G, Kang MC, Heo S-J, Je J-G, Jeon Y-J. A comparative study of Sargassum horneri Korea and China strains collected along the coast of Jeju Island South Korea: its components and bioactive properties. Algae. 2018;33:341-9.

Kim MM, Rajapakse N, Kim SK. Anti-inflammatory effect of Ishige okamurae ethanolic extract via inhibition of NF-kappaB transcription factor in RAW 264. 7 cells. Phytother Res. 2009;23:628-34.

Kubo N, Douke A, Nishigaki T, Tsuji G. Development and characterization of simple sequence repeat markers for genetic analyses of Sargassum horneri (Sargassaceae, Phaeophyta) populations in Kyoto, Japan. J Appl Phycol. 2017; 29:1729-33.

Li KK, Shen SS, Deng X, Shiu HT, Siu WS, Leung PC, Ko CH, Cheng BH. Dihydrofisetin exerts its anti-inflammatory effects associated with suppressing ERK/p38 MAPK and Heme Oxygenase-1 activation in lipopolysaccharide-stimulated RAW 264.7 macrophages and carrageenaninduced mice paw edema. Int Immunopharmacol. 2018:54:366-74.

Lund AK. 6.14 - oxidants and endothelial dysfunction. In: McQueen CA, editor. Comprehensive toxicology (Second Edition). Oxford: Elsevier; 2010. p. 243-74.

Ma AC, Chen Z, Wang T, Song N, Yan Q, Fang YC, Guan HS, Liu HB. Isolation of the molecular species of monogalactosyldiacylglycerols from brown edible seaweed Sargassum horneri and their inhibitory effects on triglyceride accumulation in 3T3-L1 adipocytes. J Agric Food Chem. 2014;62:11157-62.

Merchant M, Morkotinis V, Hale A, White M, Moran C. Crocodylian nuclear factor kappa B. Comp Biochem Physiol B Biochem Mol Biol. 2017;213:28-34.

Mulgund A, Doshi S, Agarwal A. Chapter 25 - the role of oxidative stress in endometriosis. In: Watson RR, editor. Handbook of fertility. San Diego: Academic Press; 2015. p. 273-81.

Nomura M, Kamogawa H, Susanto E, Kawagoe C, Yasui H, Saga N, Hosokawa M, Miyashita K. Seasonal variations of total lipids, fatty acid composition, and fucoxanthin contents of Sargassum horneri (Turner) and Cystoseira hakodatensis (Yendo) from the northern seashore of Japan. J Appl Phycol. 2012;25:1159-69.

Pugh TJ, Sartor Cl, O'Neil B, Raben D. Chapter 5 - biologics and their interactions with radiation. In: Gunderson LL, Tepper JE, editors. Clinical radiation oncology (Third Edition). Philadelphia: W.B. Saunders; 2012. p. 83-94.

Salter DM. 8 - Connective tissue responses to mechanical stress. In: Hochberg MC Silman AJ, Smolen JS, Weinblatt ME, Weisman MH, editors. Rheumatology (sixth edition). Philadelphia: Content Repository Only! 2015. p. 61-4.

Sanjeewa KKA, Fernando IPS, Kim EA, Ahn G, Jee Y, Jeon YJ. Anti-inflammatory activity of a sulfated polysaccharide isolated from an enzymatic digest of brown seaweed Sargassum horneri in RAW 264.7 cells. Nutr Res Pract. 2017;11:3-10

Surh Y-J, Chun K-S, Cha H-H, Han SS, Keum Y-S, Park K-K, Lee SS. Molecular mechanisms underlying chemopreventive activities of anti-inflammatory phytochemicals: down-regulation of COX-2 and iNOS through suppression of NF-kB activation. Mutat Res Fundam Mol Mech Mutagen. 2001;480-481:243-68. 
Wijesinghe W, Jeon Y-J. Biological activities and potential cosmeceutical applications of bioactive components from brown seaweeds: a review. Phytochem Rev. 2011;10:431-43.

Xie X, Wang G, Pan G, Sun J, Li J. Development of oogonia of Sargassum horneri (Fucales, Heterokontophyta) and concomitant variations in PSII photosynthetic activities. Phycologia. 2014;53:10-4.

Zielinski MR, Krueger JM. Chapter 48 - inflammation and sleep. In: Barkoukis TJ, Matheson JK, Ferber R, Doghramji K, editors. Therapy in sleep medicine. Philadelphia: W.B. Saunders; 2012. p. 607-16.

Ready to submit your research? Choose BMC and benefit from:

- fast, convenient online submission

- thorough peer review by experienced researchers in your field

- rapid publication on acceptance

- support for research data, including large and complex data types

- gold Open Access which fosters wider collaboration and increased citations

- maximum visibility for your research: over $100 \mathrm{M}$ website views per year

At $B M C$, research is always in progress.

Learn more biomedcentral.com/submissions 